\title{
Development of a Series Hybrid Electric Aircraft Pushback Vehicle: A Case Study
}

\author{
Scott Cash ${ }^{1}$, Quan Zhou${ }^{1}$, Oluremi Olatunbosun ${ }^{1}{ }^{*}$, Hongming $X^{1}{ }^{1}$, Sean Davis ${ }^{2}$, Robin Shaw ${ }^{3}$ \\ ${ }^{1}$ Department of Mechanical Engineering, University of Birmingham, Birmingham, UK \\ ${ }^{2}$ Textron, Cheltenham, UK \\ ${ }^{3}$ Hyperdrive Innovation Ltd., Sunderland, UK \\ Email: *o.a.olatunbosun@bham.ac.uk
}

How to cite this paper: Cash, S., Zhou, Q., Olatunbosun, O., Xu, H.M., Davis, S. and Shaw, R. (2019) Development of a Series Hybrid Electric Aircraft Pushback Vehicle: A Case Study. Engineering, 11, 33-47. https://doi.org/10.4236/eng.2019.111004

Received: December 10, 2018

Accepted: January 20, 2019

Published: January 23, 2019

Copyright (c) 2019 by author(s) and Scientific Research Publishing Inc. This work is licensed under the Creative Commons Attribution International License (CC BY 4.0).

http://creativecommons.org/licenses/by/4.0/

\section{(c) (i) Open Access}

\begin{abstract}
The work presented in this paper is a progression to previous research which developed an overcurrent-tolerant prediction model. This paper presents some of the modelling and development techniques used for the previous research, but more emphasis is placed on the requirements of the case study; whereby an aeroplane pushback tug is converted into a series Hybrid Electric Vehicle (HEV). An iterative design process enabled the traction motor, transmission, generator and battery pack parameters to be tailored for this vehicle's unique duty cycle. A MATLAB/Simulink model was developed to simulate the existing internal combustion engine powertrain as well as the series HEV equivalent for comparative analysis and validation purposes. The HEV design was validated by comparing the simulation results to recorded real-world data collected from the existing vehicle (torque, speeds etc.). The HEV simulations provided greater fuel savings and reduced emissions over the daily duty cycle in comparison to the existing vehicle.
\end{abstract}

\section{Keywords}

Hybrid Electric Vehicle, HEV, Design, Development, Traction Motor

\section{Introduction}

Carbon Dioxide $\left(\mathrm{CO}_{2}\right)$ is the primary greenhouse gas affecting global climate change [1] [2] [3]. Nearly $18 \%$ of the global $\mathrm{CO}_{2}$ emissions generated each year from the burning of fossil fuels come from the transportation sector [4] [5]. It has been estimated that around 29,000 deaths each year are attributed to exposure to fine Particulate Matter (PM) in the UK alone [6] [7]. Nitrous Oxides (NOx) in the presence of ultraviolet light can become converted into photo- 
chemical smog, extended exposure to this causes eye irritation and can impair respiratory functions [8] [9]. The environmental impact and health issues from the emission generated from Internal Combustion Engines (ICE) has thus motivated greater research into Hybrid Electric Vehicles (HEV) and pure Electric Vehicles (EV) in a wide range of transportation sectors [10] [11] [12] [13].

An aeroplane pushback vehicle is required to move aeroplanes away from airport terminals and occasionally tow them across an airfield to the hangar to receive routine maintenance. Conventional pushback vehicles use high capacity Internal Combustion Engines (ICE) with a number of transmission ratios which are rarely fully exercised. Between pushback operations, the vehicle might rest for long periods until it is needed again. The ICE remains idling whenever the vehicle is resting to avoid any ICE start-up difficulties (particularly during cold weather). This is because airports deal with a high volume of aeroplane arrivals and departures each day, so an aeroplane tug failing to turn on could cause dramatic delays. These long idle times significantly increase the total fuel consumption and output emissions over the working day. One major advantage of a HEV pushback vehicle is that the generator is able to be turned off during the rest periods as long as there is enough energy stored in the Energy Storage System (ESS). Ideally, a series HEV would operate in fully electric mode for a substantial portion of the duty cycle to minimise fuel costs and output emissions. While the design methodologies for various light and heavy commercial vehicles have been reported in the literature [14] [15] [16] none has addressed the unique operational duty cycles of the aeroplane pushback vehicle consisting of diverse operations including series of short duration peak power operations, medium power, longer duration operations and high speed, low power operations. This paper establishes a development strategy for a hybrid vehicle with this type of unique and unusual duty cycle.

The proposed aeroplane tug will have a series hybrid topology as shown in Figure 1, incorporating an electric motor for traction, an engine-generator (genset) for electric power generation, and a battery pack to store electrical energy. The ICE and the HEV models were created in MATLAB/Simulink using standard vehicle dynamic equations and a new torque control strategy was incorporated into the traction motor. Electrical power management techniques were investigated to ensure the battery pack does not overcharge or over-discharge as well as prolonging the life of the genset. Section 2 will discuss some of the methodology and design criteria for the aeroplane pushback HEV. Further information not contained within this paper can be found from the author's previous research [17]. Section 3 will analyse the results of the final pushback vehicle.

\section{Methodology}

Effective HEV design requires optimising the choice of mechanical and electrical components to meet the vehicle's target dynamic performance with the longest 


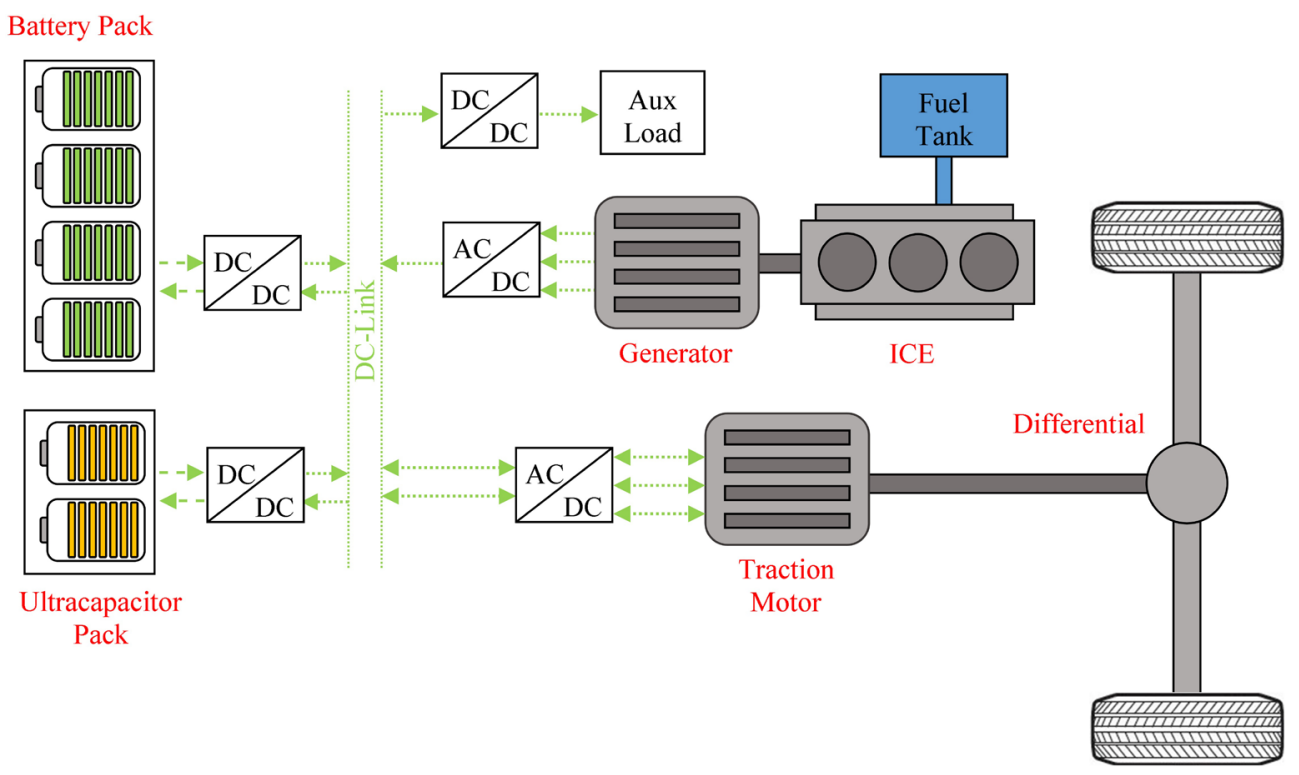

Figure 1. Conventional series HEV powertrain topology showing the main components required.

driving range possible [18]. Numerous design iterations are often deliberated to ensure the mechanical and electrical parameters of the system allow the vehicle to achieve its target performance objectives. Part of the iterative process also requires compromising between other vehicle constraints such as the unloaded performance, cost, and component size. The pushback vehicle must be able to generate a large towing tractive force, but also have a relatively high top speed to travel quickly between pushback operations ( $\sim 30 \mathrm{kph}$ unloaded). The airport regulations and aeroplane manufacturers require that the tug must be able to generate a minimum tractive force for each aeroplane weight class the tug is designated to tow, an example of the tractive force requirements for a Boeing 737-7 is referenced [19]. Therefore a suitable combination of traction motor, transmission ratios and final drive ratios should be used to meet these regulations. As the mass of the conventional pushback vehicle is already very large, the additional mass of a battery pack which would normally be a constraint in the vehicle design is not of concern for this application.

The iterative design process for this vehicle was separated into two areas; finding appropriate mechanical components that will allow the vehicle to achieve its target longitudinal dynamics and the electrical storage/generation parameters that would allow the vehicle to fulfil its mission. The mechanical components under investigation include specifying a traction motor with appropriate torque-speed characteristics, final drive ratio and transmission ratios. The vehicle dynamics iterations target was to enable the vehicle achieve a performance comparable to the ICE equivalent vehicle. The vehicle dynamics of the hybrid vehicle must be comparable to the ICE to be a viable equivalent for customers. The electrical components under investigation include battery pack capacity, battery pack peak power outputs, genset size, and genset control methods. 
A Fuzzy Logic (FL) speed controller was used to control the speed of the conventional pushback vehicle model and the HEV model which attempts to follow a target velocity profile by generating appropriate accelerator $\gamma_{a c c} \in[0,1]$ and brake pedal $\gamma_{b r k} \in[0,1]$ activation levels [20]. The membership functions for the FL speed controller are given in Table 1 and the rule base is given in Figure 2. This controller uses the longitudinal velocity error $\Delta V_{x}$ (1) between the target velocity $V_{x}^{*}$ and the instantaneous velocity $V_{x}$ at time $t$ as the first input and its time derivative as the second input to generate a suitable pedal activation level.

An input range of $\pm 5 \mathrm{kph}$ in Figure 2(a) is used for the controller's first input $\Delta V_{x}$ because this offers the best trade-off between a low steady-state velocity error and control realism. Reducing this input range improves the steady-state error of the vehicle, but it also results in erratic pedal control. The second input range $\pm 20 \mathrm{kph} / \mathrm{s}$ in Figure 2(b) for the time derivative of $\Delta V_{x}$ is used because $20 \mathrm{kph} / \mathrm{s}$ approaches the acceleration ability of high performance sports vehicles (0 - $60 \mathrm{mph}$ time $\approx 4.8 \mathrm{~s})$. Most typical drivers would accept $\pm 20 \mathrm{kph} / \mathrm{s}$ to be a large acceleration value.

A controller output with a magnitude 1 indicates that the accelerator or brake pedal is fully activated. Positive speed controller outputs represent accelerator pedal activation levels and negative outputs represent brake pedal activation levels. An accelerator pedal activation level corresponds to the driver requesting a motor torque output to either accelerate the vehicle or maintain a steady cruising speed.

$$
\Delta V_{x}(t)=V_{x}^{*}(t)-V_{x}(t)
$$

A vehicle model created in MATLAB/Simulink contains the basic forces acting upon the vehicle. The tractive force $F_{\text {Traction }}$ at the road-wheel interface (2), the rolling resistance $F_{\text {Rolling }}$ of the tyres (3), the aerodynamic drag $F_{\text {Aero }}$ and the brake force $F_{\text {Brake }}(5)$ are all included in the model [16] [21] [22].

$$
F_{\text {Traction }}=\frac{\tau_{P M} N_{f d} N_{T} \eta_{f d}}{R}
$$

Table 1. FL Speed Controller rule base

\begin{tabular}{ccccccccc}
\hline & & \multicolumn{7}{c}{$\Delta V_{x}$} \\
\hline & -3 & -2 & -1 & 0 & 1 & 2 & 3 \\
\hline & -3 & -1 & 0 & 0 & 1 & 2 & 2 & 3 \\
& -2 & -2 & -1 & 0 & 0 & 1 & 2 & 3 \\
& -1 & -2 & -2 & -1 & 0 & 1 & 2 & 3 \\
$\mathrm{~d} t\left(\Delta V_{x}\right)$ & 0 & -3 & -2 & -1 & 0 & 1 & 1 & 3 \\
& $\mathbf{1}$ & -3 & -2 & -1 & 0 & 1 & 1 & 2 \\
& 2 & -3 & -2 & -1 & 0 & 0 & 1 & 2 \\
& 3 & -3 & -2 & -2 & -1 & 0 & 0 & 1 \\
\hline
\end{tabular}




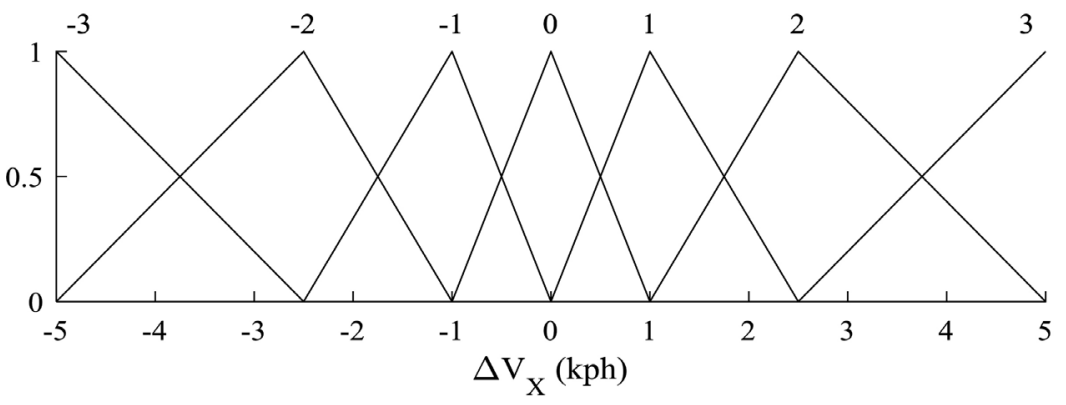

(a)

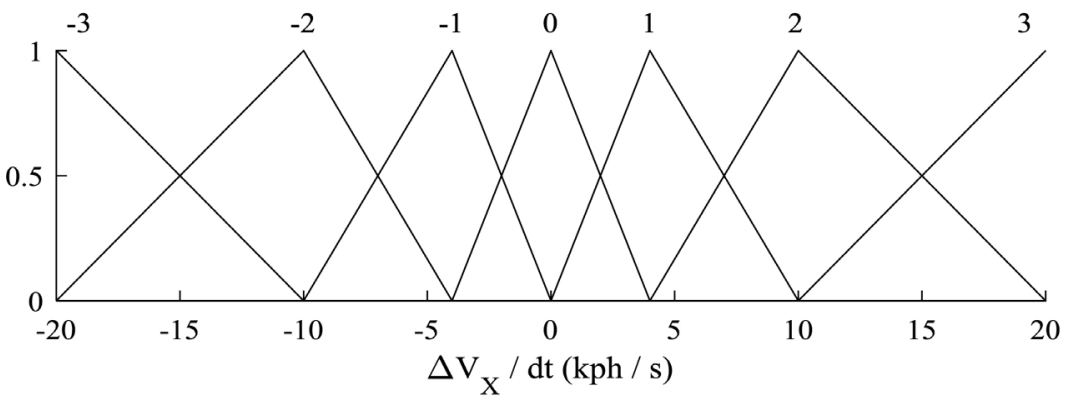

(b)

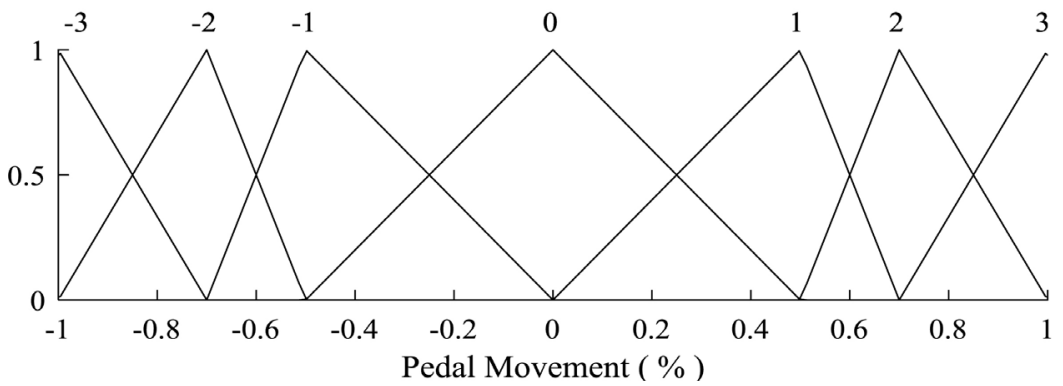

(c)

Figure 2. FL speed controller membership functions, (a) Input 1: $\Delta V_{x}$, (b) Input 2: $\frac{\Delta V_{x}}{\mathrm{~d} t}$, (c) Output: Pedal movement.

$$
\begin{gathered}
F_{\text {Rolling }}=\left(M_{\text {Veh }}+M_{\text {Aero }}\right) g f_{r} \\
F_{\text {Aero }}=\frac{1}{2} C_{D} \rho_{\text {air }} A_{f} V_{x}^{2} \\
F_{\text {Brake }}=\gamma_{\text {brk }} F_{B-\max }
\end{gathered}
$$

The tractive force requires the output torque from the prime mover $\tau_{P M}$, gear ratio of the final drive $N_{f d}$, transmission ratio $N_{T}$, their combined efficiency $\eta_{T f d}$ and the wheel's rolling radius $R$. As the vehicle under investigation is an aeroplane pushback vehicle, the mass of the aeroplane $M_{\text {Aero }}$ is included in (3) to account for the additional rolling resistance from the aeroplane. Removal of $M_{\text {Aero }}$ allows this vehicle model to be used for conventional passenger vehicle simulations. The aerodynamic drag force $F_{\text {Aero }}$ requires the frontal area of the vehicle $A_{f}$, coefficient of aerodynamic drag $C_{D}$ and the density of the air $\rho_{\text {air }}$. The combined brake force $F_{\text {Brake }}$ uses a linear relationship between the brake pedal activation level $\gamma_{b r k}$ and the maximum brake force available to the road-wheel conditions $F_{B-\max }$. The effective additional towing mass of the vehicle $M_{r}$ (6) is dependent on the rotational inertias of the prime mover $I_{P M}$, 
transmission $I_{T}$, final drive $I_{F d}$ and the wheels $I_{W h}$ [17]. The longitudinal acceleration $a_{x}$ of the vehicle is then calculated using (7), and the rotational speed of the prime mover $\omega_{P M}$ is then calculated using (8) [17].

$$
\begin{gathered}
M_{r}=\left(I_{P M} N_{f d}^{2}+I_{T} N_{f d}^{2}+I_{F d} N_{f d}^{2}+I_{W h}\right) \frac{1}{R^{2}} \\
F_{\text {Traction }}-F_{\text {Brake }}-F_{\text {Aero }}-F_{\text {Rolling }}=\left(M_{\text {Veh }}+M_{\text {Aero }}+M_{r}\right) a_{x} \\
\omega_{P M}=\frac{V_{x} N_{f d} N_{T}}{R}
\end{gathered}
$$

Details of the parameters of the existing vehicle are shown in Table 2. It uses an IC engine with the torque-speed profile provided in Table 3, along with a final drive ratio and three gear ratios $N_{T}$. Gear ratio 1 is used for the towing operation, gear ratio 2 is used for the maintenance runs, and gear ratio 3 is used for the unloaded solo runs. These gears cannot change while the vehicle is moving

\begin{tabular}{|c|c|c|}
\hline Parameter & Symbol & Value \\
\hline \multicolumn{3}{|l|}{ ICE only } \\
\hline Transmission ratios [1] [2] [3] & $N_{T}$ & {$[5.8,2.5,0.98]$} \\
\hline Transmission inertia $\left(\mathrm{kg} \mathrm{m}^{2}\right)[1][2][3]$ & $I_{T}$ & {$[0.14,0.1,0.08]$} \\
\hline Final drive ratio & $N_{f d}$ & 13 \\
\hline Final drive inertia $\left(\mathrm{kg} \mathrm{m}^{2}\right)$ & $I_{F d}$ & 0.2 \\
\hline Final drive efficiency & $\eta_{f d}$ & 0.98 \\
\hline Driveshaft inertia $\left(\mathrm{kg} \mathrm{m}^{2}\right)$ & $I_{F d}$ & 0.17 \\
\hline ICE inertia $\left(\mathrm{kg} \mathrm{m}^{2}\right)$ & $I_{I C E}$ & 0.08 \\
\hline \multicolumn{3}{|l|}{ ICE and HEV shared } \\
\hline Vehicle mass $(\mathrm{kg})$ & $M_{\text {Veh }}$ & 16,000 \\
\hline Coefficient of drag & $C_{D}$ & 0.8 \\
\hline Frontal area $\left(\mathrm{m}^{2}\right)$ & $A_{f}$ & 6.8 \\
\hline Wheel radius $(\mathrm{m})$ & $R$ & 0.575 \\
\hline Coefficient of rolling resistance (\%) & $f_{r}$ & 2 \\
\hline Max brake force $(\mathrm{N})$ & $F_{B-\max }$ & 800 \\
\hline Air density $\left(\mathrm{kg} \mathrm{m}^{-3}\right)$ & $\rho_{\text {air }}$ & 1.22 \\
\hline Wheel inertia $\left(\mathrm{kg} \mathrm{m}^{2}\right)$ & $I_{w h}$ & 2.4 \\
\hline
\end{tabular}
Table 2. Vehicle parameters of the typical ICE powered pushback vehicle to be converted into a $\mathrm{HEV}$.

Table 3. ICE Speed-Torque characteristics for the conventional aeroplane pushback vehicle.

\begin{tabular}{cccccccccc}
\hline Speed (rpm) & 600 & 700 & 900 & 1100 & 1300 & 1500 & 1900 & 2300 & 2500 \\
Torque (Nm) & 595 & 630 & 741 & 864 & 987 & 990 & 932 & 915 & 830 \\
\hline
\end{tabular}


and must be set before the operation begins. The ICE is accompanied by a fuel consumption map as shown in Figure 3 and a series of emissions maps shown in Figure 4 which show the $\mathrm{CO}, \mathrm{NO}_{\mathrm{x}}, \mathrm{PM}$, Hydrocarbons $(\mathrm{HC})$ and fuel consumption

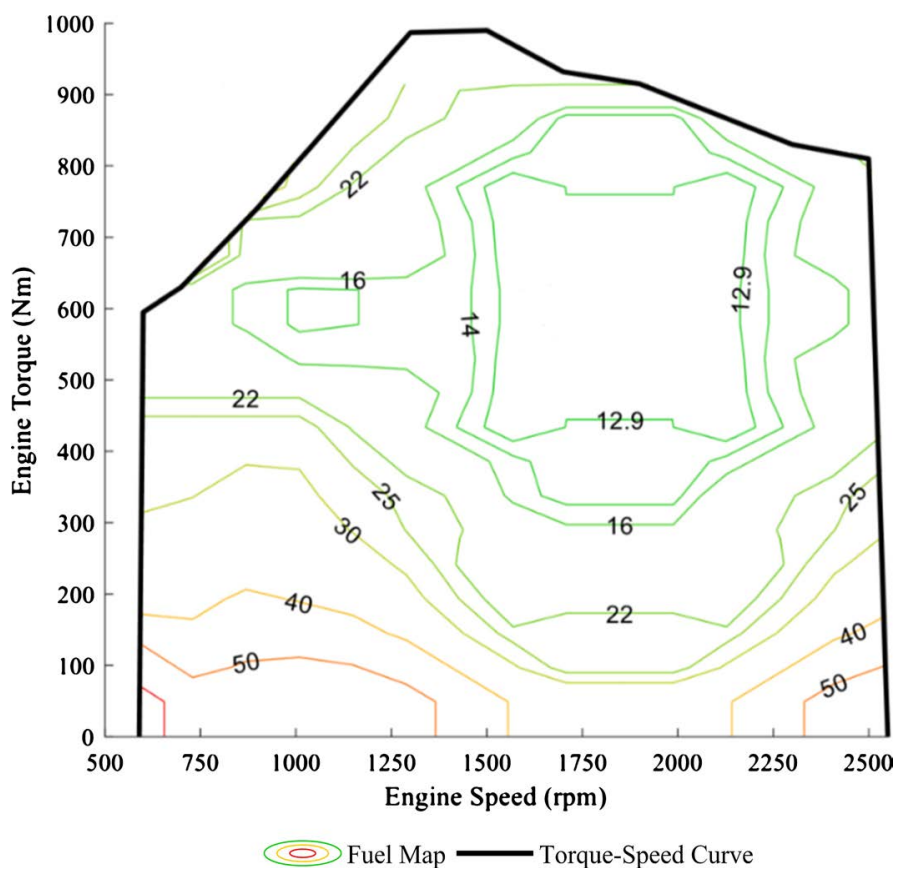

Figure 3. Convention ICE powered pushback vehicle torque-speed curve and fuel map (L/hr).
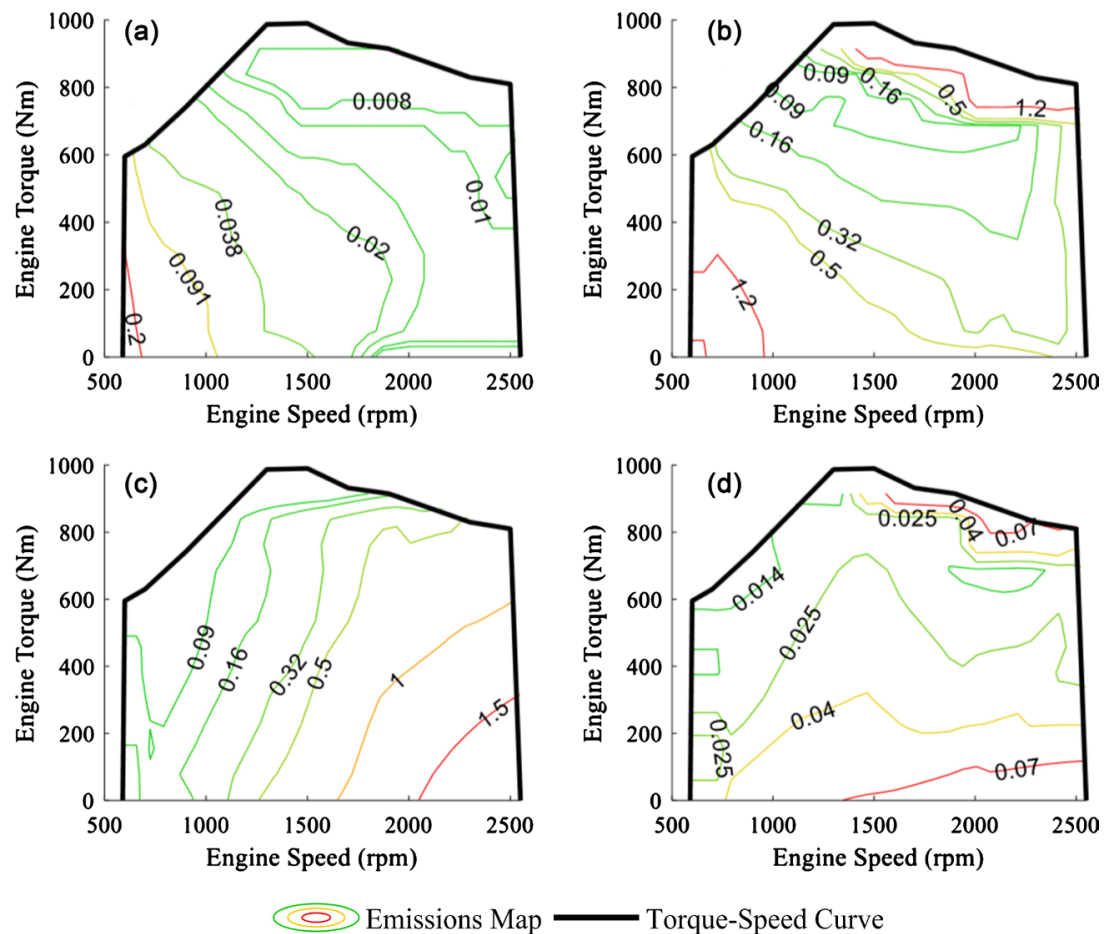

Figure 4. Convention ICE powered pushback vehicle emissions maps, (a) Hydrocarbons (HC) (g/s), (b) Carbon Monoxide (CO) (g/s), (c) Nitrous Oxides (NOx) (g/s), (d) Particulate Matter (PM) (g/s). 
for each operating point and allow the vehicle model to predict the engine's emissions over the duty cycle.

A traction motor typically has a continuous operating region and an overcurrent region as shown in Figure 5. The continuous operating region limits the motor's supply current to prevent overheating. The overcurrent region permits a larger supply current for a short amount of time to permit a higher torque output. As this increases the rate of temperature increase, this zone can only be utilised for a short period of time. The time period for overcurrent is usually publically available from motor suppliers. The rate of change in temperature using this model is estimated using the position of the output motor torque $\delta_{\tau} \in[0,1]$ between the peak continuous torque $\widehat{\tau_{C}}\left(\omega_{m}\right)$ and the peak overcurrent torque $\widehat{\tau_{O}}\left(\omega_{m}\right)$. A diagrammatical view of how $\delta_{\tau}$ is obtained is shown in Figure 5 where $\delta_{\tau}\left(\omega_{m 1}\right)>\delta_{\tau}\left(\omega_{m 2}\right)$. This model is based on the overcurrent-tolerant prediction model developed by the authors [17].

When the driver of the vehicle model activates the accelerator pedal $\gamma_{\text {acc }} \in[0,1]$, the motor model initially attempts to access the overcurrent torque curve, where $P M=O$ in (9). For a series-HEV or pure EV, the torque will be fully accommodated by the traction motor. For a parallel or power-spit HEV, the fraction of the command torque required to be supplied by the traction motor will take the role of the required output torque in (9).

$$
\tau_{P M}\left(\omega_{m}, \gamma_{a c c}\right)=\gamma_{a c c} \widehat{\tau_{P M}}\left(\omega_{m}\right)
$$

where $P M=O, C$.

An efficiency map can be used to find the motor's electrical power consumption at each point on the torque-speed curve using Equation (10). The tug also has a high auxiliary power demand from providing power to the aeroplane's air conditioning during pushback operations, warning lights, heating, and ventilation to the cabin. It is assumed that the auxiliary power would be constant throughout the duty cycle to indicate a worst case scenario.

$$
\frac{\tau_{P M} \omega_{P M}}{\eta_{e}\left(\omega_{P M}, \tau_{P M}\right)}
$$

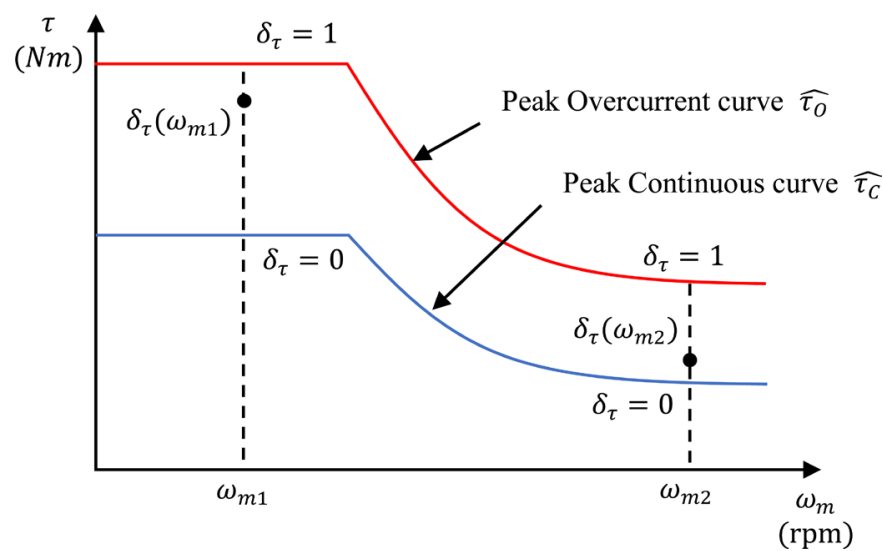

Figure 5. Diagrammatical view of how $\delta_{\tau}$ is generated. 
The torque-speed characteristics of an ICE are simulated in a similar method to the simplified traction motor models using Equation (9) by replacing $P M=I C E$ or via an equivalent throttle map. The full load torque-speed curve of the traction motors are now representative of the ICE peak torque-speed curve $\widehat{\tau_{I C E}}$ and the efficiency maps of Equation (10) are replaced by the ICE's fuel consumption and tailpipe output emissions maps.

The APU is defined by numerous criteria including; output power $(\mathrm{kW})$, fuel consumption $(\mathrm{L} / \mathrm{hr})$ and output emissions $(\mathrm{g} / \mathrm{s})$. These parameters are integrated over time to produce the total fuel consumption, total output emissions and total energy provided by the APU.

The electrical storage/generation is based around the State of Energy (SOE) of the battery pack and the net power of the DC link. The net DC link power is integrated to represent the energy supply/demand of the battery pack and is added to the battery pack's initial energy at the start of the duty cycle. The battery SOE control uses a relay system which at its core revolves around upper and lower SOE limits to turn on/off the generator. The genset provides electrical power to the DC link to directly power the traction motor or charge the battery pack. The genset can only operate in one of 3 ways; full power, idle and off. During full power operation the genset consumes fuel at its rated value, when at idle the fuel consumption is reduced. Idle mode aids in the warm-up and cool-down of the genset to prolong longevity. The electrical power required for pushback operations is larger than what most battery packs can provide, therefore the genset must be turned on during pushback operations to provide additional power to the DC link.

For the hybrid aeroplane tug to truly be comparable with the ICE counterpart, the battery pack SOE should be at the upper limit by the end of the duty cycle. This is analogous to the ICE tug having the fuel tank filled at the end of the working day. Therefore, once the last pushback operation of the duty cycle is completed, the genset will turn on to begin charging the battery pack while the tug returns to the overnight storage area. The genset will remain on until the SOE reaches the upper limit where all auxiliary power can then be turned off.

Duty cycle data was recorded from the conventional ICE powered pushback vehicle (engine speed, output torque, longitudinal velocity, etc.) via the CAN bus. This data was used to construct a target duty cycle for the HEV to follow. The pushback vehicle's duty cycle, obtained from several days' actual operation in the field, is broken down into four major areas as shown in Table 4 and explained as follows:

- Low velocity pushback operations of heavy aircraft. This scenario occurs when the pushback vehicle is required to move aeroplanes away from the airport terminal.

- Medium velocity towing operations of medium weight aircraft. This represents a maintenance run where the pushback vehicle tows an empty aeroplane for a longer duration across an airfield to receive routine maintenance. 
- High velocity unloaded solo runs. Here the pushback vehicle is travelling back and forth between resting areas where it must wait until the next operation.

- Stationary resting periods. Here the vehicle is waiting for its next pushback operation. All hazard warning lights must remain on as the vehicle is still on the operating airfield.

\section{Results}

The final tug design parameters are given in Table 5 where a single large traction motor using a 2-speed transmission was used. The torque-speed curves for this motor and an efficiency map based on a 9-phase $245 \mathrm{~kW}$ IM is shown in Figure 6 [23]. A high gear ratio $N_{T-f d 1}$ is used during towing and maintenance operations as it achieves the minimum tractive force requirement. A low gear ratio $N_{T-f d 2}$ was chosen for unloaded solo runs which allows the vehicle to reach its top unloaded speed.

The traction motor's torque-speed output throughout the duty cycle is shown of Figure 7 in relation to the chosen traction motor's torque curves. This particular traction motor and gear ratio combination is oversized for the current duty cycle allowing room for future expansion of aeroplane weight class compatibility. It can be seen that the required torque does not exceed the motor's continuous torque curve, enabling the traction motor to repeat the duty cycle operations indefinitely without the risk of overheating the electrical components. The results in Figure 8 show that the dynamic and electrical performance conditions of the hybrid aeroplane tow vehicle have been met.

Table 4. Pushback operation descriptions for the typical ICE vehicle and the HEV equivalent.

\begin{tabular}{ccccc}
\hline Operation & No. of Operations & $\boldsymbol{M}_{\text {Aero }}$ (Tonne) & Target Speed (kph) & Time $(\mathbf{s})$ \\
\hline Solo & 14 & 0 & 27 & 170 \\
Tow & 14 & 250 & 5 & 385 \\
Maintenance & 2 & 160 & 10 & 1870 \\
Standby & - & 0 & 0 & -
\end{tabular}

Table 5. Aeroplane pushback HEV equivalent parameters

\begin{tabular}{cc}
\hline Parameter & Value \\
\hline Continuous power $(\mathrm{kW})$ & 245 \\
Continuous torque $(\mathrm{Nm})$ & 2200 \\
Overcurrent power $60 \sec (\mathrm{kW})$ & 250 \\
Overcurrent torque $60 \sec (\mathrm{Nm})$ & 2700 \\
Maximum motor speed $(\mathrm{rpm})$ & 3252 \\
$N_{\text {T-fd1 }}$ & 50.28 \\
$N_{\text {T-fd2 }}$ & 28 \\
\hline
\end{tabular}




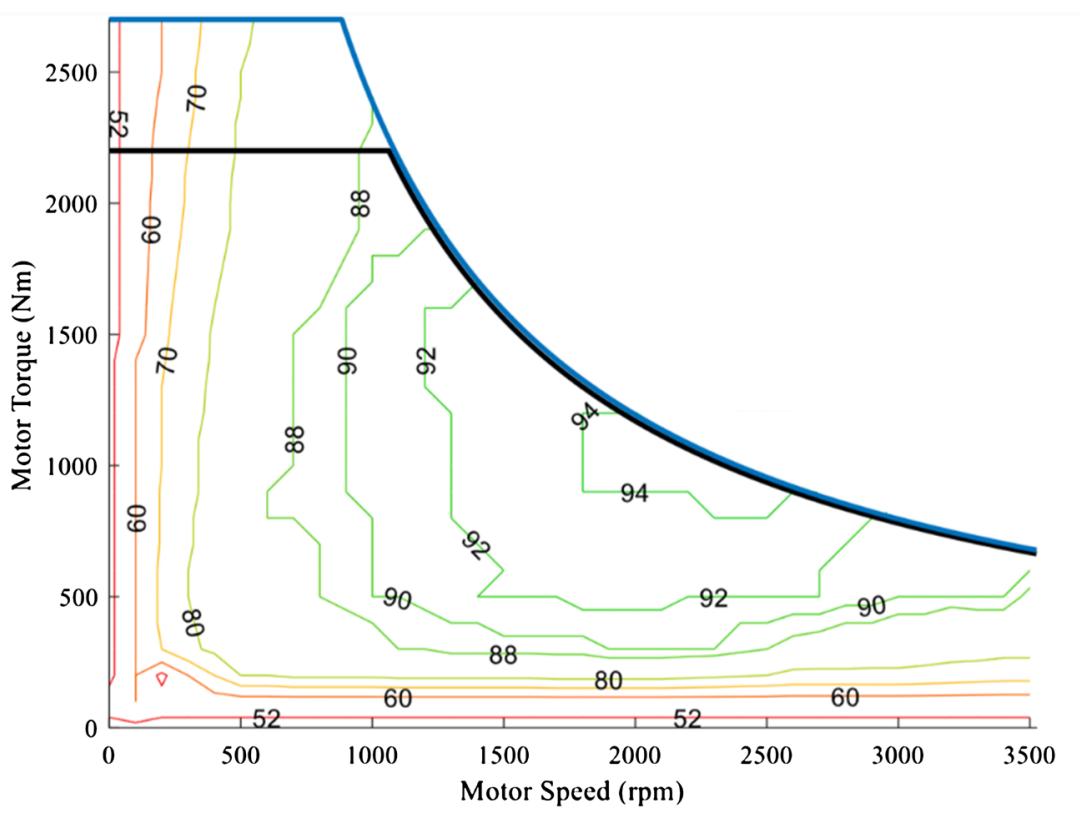

Efficiency Map

Continuous Torque Speed Curve

Overcurrent Torque Speed Curve

Figure 6. Torque Speed curves and efficiency map (\%) for the traction motor used in HEV pushback vehicle.

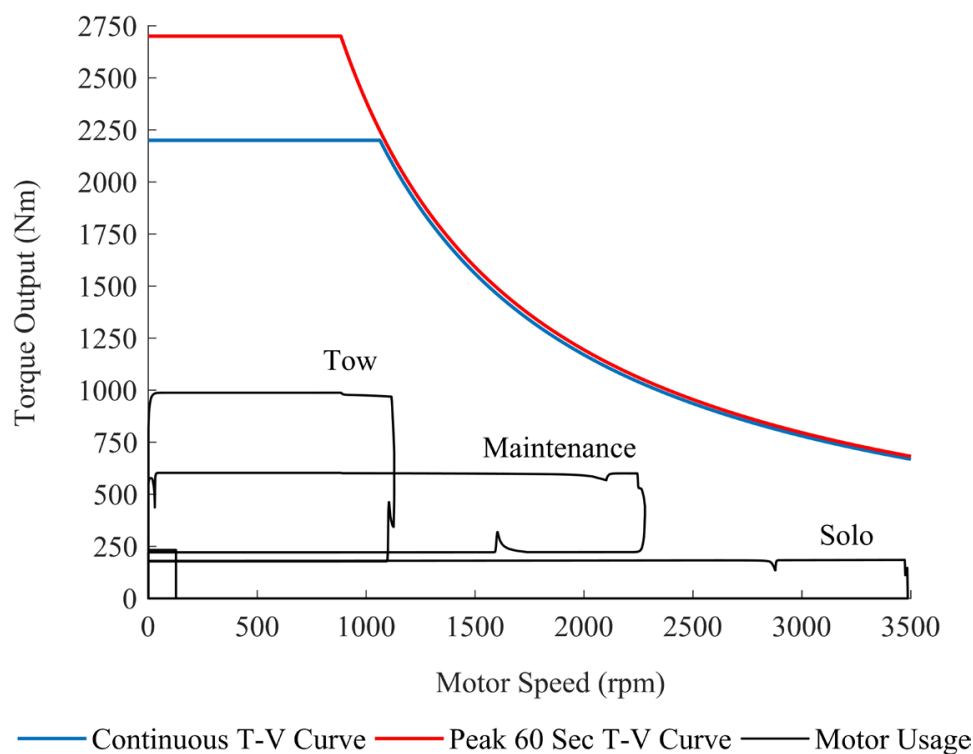

Figure 7. Traction motor usage over the duty cycle.

The hybrid vehicle's dynamic profile is comparable to the target ICE counterpart, the battery SOE remains within safe working limits and the genset does not turn on/off rapidly throughout the duty cycle.

The blue shaded areas of Figure 8 show that the genset is providing full power to the DC-Link and that the traction motors are fully utilising this power during towing operations with the surplus power demand coming from the battery pack. The yellow shaded regions show that the genset provides full power to the DC-Link and the battery pack is being charged. The hybrid tug 


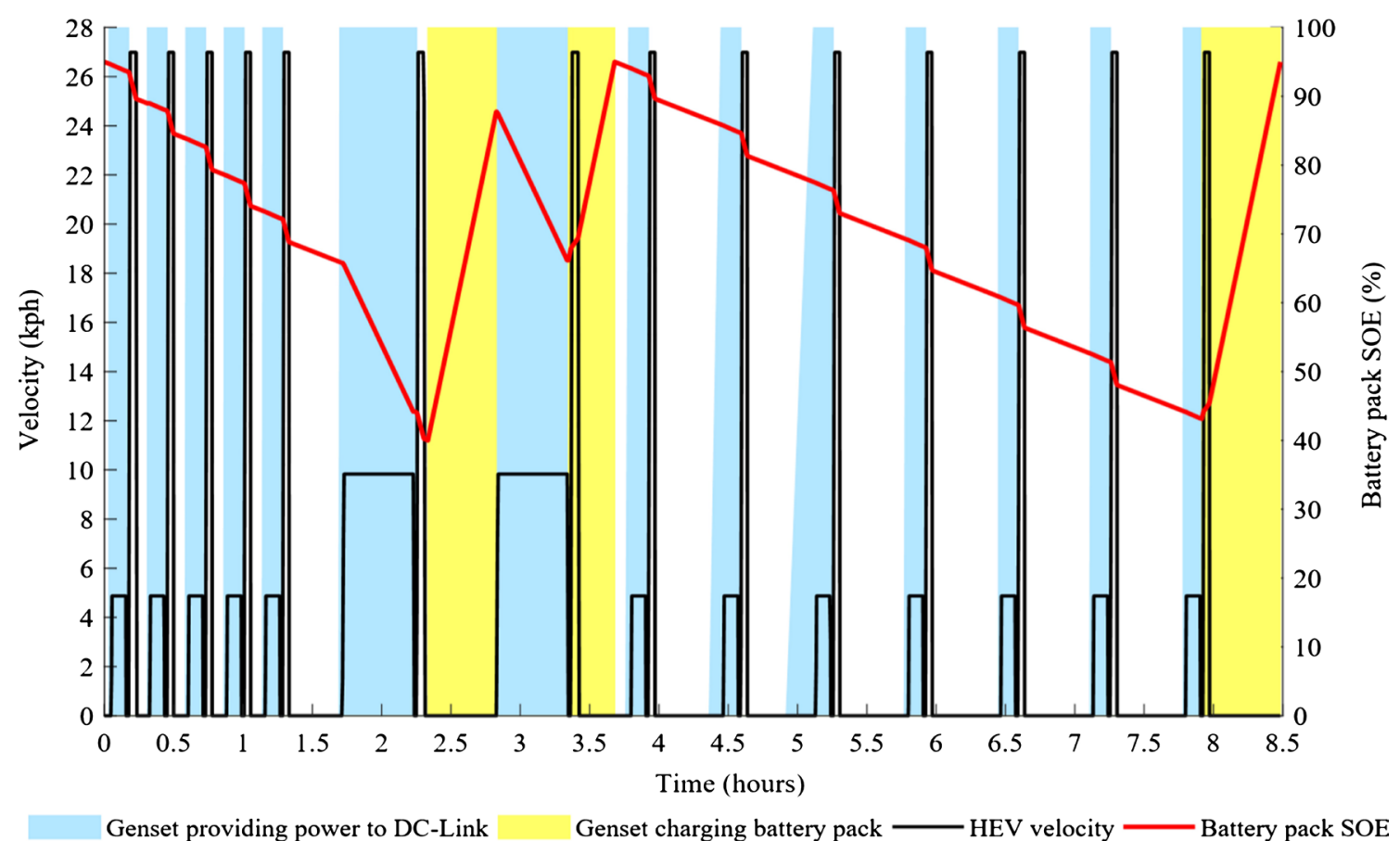

Figure 8. Velocity profile and battery pack SOE over the complete duty cycle.

Table 6. Aeroplane pushback vehicle powertrain configuration energy requirement and fuel consumption comparison.

\begin{tabular}{cccc}
\hline Powertrain configuration & Energy required (kWh) & Fuel consumed (L) & Difference (\%) \\
\hline ICE & - & 189.7 & - \\
HEV Configuration 2 & 261 & 91.22 & $51.9 \%$ \\
\hline
\end{tabular}

only used $91.22 \mathrm{~L}$ of fuel over the duty cycle compared to the $189.7 \mathrm{~L}$ used by the ICE vehicle, i.e. 51.9\% reduction, as shown in Table 6. Assuming that the genset provided a similar reduction in engine emissions, the total volume of $\mathrm{CO}, \mathrm{NO}_{\mathrm{x}}, \mathrm{PM}$, and HC's at the end of the duty cycle was also reduced.

\section{Conclusion}

This paper presented some of the design and modelling methods for a series hybrid conversion for an aeroplane pushback tug with comparable performance to the previous ICE counterpart. The design constraints of this vehicle were discussed along with their effect on the final vehicle design. The HEV equivalent managed to meet the target dynamic requirements and remained within the electrical operational boundaries. The final vehicle design proved to be overpowered for this application as the regulatory requirements had overruled the optimal design, but left room for future compatibility with larger aeroplanes. The hybrid vehicle reduced fuel consumption by around $52 \%$ over the ICE equivalent vehicle, reducing the overall fuel costs with an equivalent reduction in engine emissions. The vehicle is currently undergoing validation experiments where the vehicle is challenged with following similar duty cycle operations to 
the ones investigated in this paper. The main constraint in this design is the regulatory requirement which overruled the optimal design. Future studies will focus on the use of an ultra-capacitor to enable the battery capacity to be reduced to save costs as well as an energy recovery system to improve the efficiency of the powertrain.

\section{Conflicts of Interest}

The authors declare no conflicts of interest regarding the publication of this paper.

\section{References}

[1] Sabine, C. and Feely, R. (2015) Encyclopedia of Atmospheric Sciences. 2nd Edition, Elsevier Ltd., Amsterdam, 10-17.

[2] Requia, W.J., Mohamed, M., Higgins, C.D., Arain, A. and Ferguson, M. (2018) How Clean Are Electric Vehicles? Evidence-Based Review of the Effects of Electric Mobility on Air Pollutants, Greenhouse Gas Emissions and Human Health. Atmospheric Environment, 185, 64-77. https://doi.org/10.1016/j.atmosenv.2018.04.040

[3] Nanaki, E.A. and Koroneos, C.J. (2016) Climate Change Mitigation and Deployment of Electric Vehicles in Urban Areas. Renewable Energy, 99, 1153-1160. https://doi.org/10.1016/j.renene.2016.08.006

[4] Ehsani, M., Ahmadi, A. and Fadai, D. (2016) Modeling of Vehicle Fuel Consumption and Carbon Dioxide Emission in Road Transport. Renewable and Sustainable Energy Reviews, 53, 1638-1648. https://doi.org/10.1016/j.rser.2015.08.062

[5] International Energy Agency (2017) $\mathrm{CO}_{2}$ Emissions from Fuel Combustion. Paris.

[6] Jain, S. (2017) Exposure to In-Vehicle Respirable Particulate Matter in Passenger Vehicles under Different Ventilation Conditions and Seasons. Sustainable Environment Research, 27, 87-94. https://doi.org/10.1016/j.serj.2016.08.006

[7] Vehicle Certification Agency (2018) Cars and Air Pollution. http://www.dft.gov.uk/vca/fcb/cars-and-air-pollution.asp

[8] Kheirbek, I., Haney, J., Douglas, S., Ito, K. and Matte, T. (2016) The Contribution of Motor Vehicle Emissions to Ambient Fine Particulate Matter Public Health Impacts in New York City: A Health Burden Assessment. Enviromental Health, 15, 89. https://doi.org/10.1186/s12940-016-0172-6

[9] Buekers, J., Holderbeke, M.V., Bierkens, J. and Panis, L.I. (2014) Health and Environmental Benefits Related to Electric Vehicle Introduction in EU Countries. Transportation Research Part D: Transport and Environment, 33, 26-38. https://doi.org/10.1016/j.trd.2014.09.002

[10] Jalalifar, M., Payam, A.F., Mirzaeian, B. and Saghaeian nezhad, S.M. (2006) Dynamic Modelling and Simulaiton of an Induction Motor with Adaptive Backstepping Design of an Input-Output Feedback Linearization Controller in Series Hybrid Electric Vehicle. International Conference on Power Electronic, Drives and Energy Systems, New Delhi, 12-15 December 2006, 1-6.

[11] Evangelou, S. and Shabbir, W. (2016) Dynamic Modeling Platform for Series Hybrid Electric Vehicles. IFAC-PapersOnLine, 49, 533-540. https://doi.org/10.1016/j.ifacol.2016.08.078

[12] Emadi, A., Rajashekara, K., Williamson, S. and Lukic, S. (2005) Topological Overview of Hybrid Electric and Fuel Cell Vehicular Power System Architectures and 
Configurations. IEEE Transactions on Vehicular Technology, 54, 763-770. https://doi.org/10.1109/TVT.2005.847445

[13] Yilmaz, M. (2015) Limitations/Capabilities of Electric Machine Technologies and Modelling Approaches for Electric Motor Design Analysis in Plug-In Electric Vehicle Applications. Renewable and Sustainable Energy Reviews, 52, 80-99. https://doi.org/10.1016/j.rser.2015.07.033

[14] Liu, X., Diallo, D. and Marchand, C. (2011) Design Methodology of Hybrid Electric Vehicle Energy Sources: Application to Fuel Cell Vehicles. International Journal of Automotive Technology, 12, 433-441. https://doi.org/10.1007/s12239-011-0051-7

[15] Millo, F., Cubito, C., Pautasso, E. and Servetto, E. (2017) Design and Development of an Hybrid Light Commercial Vehicle. Energy, 136, 90-99. https://doi.org/10.1016/j.energy.2016.04.084

[16] Ehsani, M., Rahman, K. and Toliyat, H. (1997) Propulsion System Design of Electric and Hybrid Vehicles. IEEE Transactions on Industrial Electronics, 44, 19-27. https://doi.org/10.1109/41.557495

[17] Cash, S., Zhou, Q., Xu, H., Olatunbosun, O., Davis, S. and Shaw, R. (2018) A New Traction Motor Sizing Strategy for a HEV/EV Based on an Overcurrent-Tolerant Prediction Model. IET Intelligent Transport Systems, 13, 1-9.

[18] Zhou, Q., Zhang, W., Cash, S., Olatunbosun, O., Xu, H. and Lu, G. (2017) Intelligent Sizing of a Series Hybrid Electric Power-Train System Based on Chaos-Enhanced Accelerated Particle Swarm Optimization. Applied Energy, 189, 588-601. https://doi.org/10.1016/j.apenergy.2016.12.074

[19] Boeing (2013) Beoing-Airport Compatability. http://www.boeing.com/resources/boeingdotcom/commercial/airports/acaps/737M AX.pdf

[20] Cash, S. and Olatunbosun, O. (2017) Fuzzy Logic Field-Oriented Control of an Induction Motor and a Permanent Magnet Synchronous Motor for Hybrid/Electric Vehicle Traction Applications. International Journal of Electric and Hybrid Vehicles, 9, 269-284. https://doi.org/10.1504/IJEHV.2017.087589

[21] Gao, D.W., Mi, C. and Emadi, A. (2007) Modeling and Simulation of Electric and Hybrid Vehicles. Proceedings of the IEEE, 95, 729-745. https://doi.org/10.1109/JPROC.2006.890127

[22] Gillesspie, T.D. (1992) Fundamentals of Vehicle Dynamics. Society of Automotive Engineers, Inc., Warrendale. https://doi.org/10.4271/R-114

[23] TM4 DANA Sumo-Specifications. https://www.tm4.com/products/direct-drive-electric-powertrain/sumo-md/ 


\section{Appendix}

\section{Nomenclature}

$T_{e} \quad$ Torque output (Nm)

$\omega_{m} \quad$ Rotor mechanical speed $\left(\mathrm{rad} \cdot \mathrm{s}^{-1}\right)$

$\omega_{b} \quad$ Base speed $\left(\mathrm{rad} \cdot \mathrm{s}^{-1}\right)$

$F_{\text {Traction }} \quad$ Traction force $(\mathrm{Nm})$

$F_{\text {Brake }} \quad$ Brake force (Nm)

$F_{\text {Rolling }} \quad$ Rolling resistance $(\mathrm{Nm})$

$F_{\text {Aero }} \quad$ Aerodynamic drag $(\mathrm{Nm})$

$N_{f d} \quad$ Final drive ratio

$N_{T} \quad$ Transmission ratio

$\eta_{f d} \quad$ Final drive efficiency

$r_{w} \quad$ Wheel rolling radius $(\mathrm{m})$

$f_{r} \quad$ Coefficient of rolling resistance

$M \quad$ Vehicle mass (kg)

$g \quad$ Acceleration of gravity $\left(\mathrm{m} \cdot \mathrm{s}^{-2}\right)$

$A \quad$ Vehicle frontal area $\left(\mathrm{m}^{2}\right)$

$C_{D} \quad$ Coefficient of aerodynamic drag

$\alpha \quad$ Throttle pedal angle (\%)

$\beta \quad$ Brake pedal angle (\%)

$\rho \quad$ Air density $\left(\mathrm{kg} \cdot \mathrm{m}^{-3}\right)$

$U \quad$ Vehicle speed $\left(\mathrm{m} \cdot \mathrm{s}^{-1}\right)$

$F_{B \max } \quad$ Maximum brake force $(\mathrm{Nm})$

$M_{r} \quad$ Effective vehicle mass $(\mathrm{kg})$

$I_{m} \quad$ Motor inertia $\left(\mathrm{kg} \cdot \mathrm{m}^{2}\right)$

$I_{F d} \quad$ Final drive inertia $\left(\mathrm{kg} \cdot \mathrm{m}^{2}\right)$

$I_{\text {Wh }} \quad$ Wheel inertia $\left(\mathrm{kg} \cdot \mathrm{m}^{2}\right)$ 